\title{
Comorbid brain disorders associated with diabetes: therapeutic potentials of prebiotics, probiotics and herbal drugs
}

\author{
Ajit Kumar Thakur ${ }^{*}$ (D), Sakshi Tyagi and Nikhila Shekhar
}

\begin{abstract}
Prevalence of diabetes and comorbid brain disorders is increasing worldwide particularly in low- and middleincome countries. Diabetes and its complications impose substantial economic costs on the developing countries. Several comorbid conditions have been described for diabetes including central nervous system (CNS) disorders. Molecular changes in CNS due to chronic hyperglycemia could be the root cause of psychiatric comorbidities in metabolic syndrome as dietary carbohydrates and proteins affect plasma concentrations of many neurotransmitters involved in brain function. Glucose metabolism play an important role related in neuroenergetics,

neurotransmission, energy storage, biosynthesis and oxidative defense. Thus, tight regulation of glucose metabolism is critical for normal brain physiology. An exaggerated symptom of depression, anxiety, and cognitive deficits are shown in diabetic animal models as well as in a population-based studies. Several studies show that many of the CNS acting drugs affected the glucose homeostasis and modulate brain physiology apart from their primary pharmacological actions. Gut-microbiota involve in the modulation of various physiological and pathological conditions of metabolic disorders and mental health by influencing the regulation of energy balance and release of neurotransmitters. Presently, no specific pharmacotherapies are available for CNS comorbidities associated with diabetes. However, some prebiotics, probiotics and herbal drugs are playing promising role in management of these CNS complications. Therefore, the evidence-based studies through translational research and clinical setup are warranted for better understanding for the relationship between brain glucose homeostasis and CNS complication as well as development of poly-pharmacologically active therapeutic drugs for the management of comorbid disorders associated with diabetic patients.
\end{abstract}

Keywords: Diabetes, CNS complications, Neurotransmitters, Glucose homeostasis, Gut-microbiota, Herbal drugs

\section{Background}

Diabetes is a chronic, metabolic disease characterized by elevated levels of blood glucose (or blood sugar), which accompany serious damage to the major vivacity of heart, blood vessels, eyes, kidneys, and brain [1]. Hyperglycemia, or raised blood sugar, is a common effect of uncontrolled diabetes and over time leads to serious damage to many of the body's systems, and increase the risk of dying prematurely [2]. The global prevalence of diabetes among adults over 18 years of age has risen from $4.7 \%$ in 1980 to $8.5 \%$ in 2014. According to World

\footnotetext{
* Correspondence: ajit.thakur@dpsru.edu.in

Neuropharmacology Research Laboratory, School of Pharmaceutical Sciences, Delhi Pharmaceutical Sciences and Research University, New Delhi 110 017, India
}

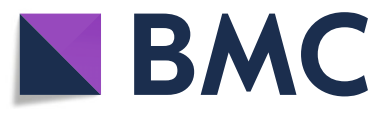

(0) The Author(s). 2019 Open Access This article is distributed under the terms of the Creative Commons Attribution 4.0 International License (http://creativecommons.org/licenses/by/4.0/), which permits unrestricted use, distribution, and reproduction in any medium, provided you give appropriate credit to the original author(s) and the source, provide a link to the Creative Commons license, and indicate if changes were made. The Creative Commons Public Domain Dedication waiver (http://creativecommons.org/publicdomain/zero/1.0/) applies to the data made available in this article, unless otherwise stated.

Health Organization (WHO) global report published recently in 2016, 422 million adults have diabetes, 1.5 million deaths are directly attributed to diabetes each year, and 1 in 3 adults aged over 18 years is overweight and 1 in 10 are obese [3]. Prevalence of diabetes is increasing worldwide, particularly in low- and middle-income countries. The causes of diabetes are complex, but the rise is due in part to increase in the number of people who are overweight, including an increase in obesity, and in a widespread lack of physical activity in daily life. In almost all high-income countries, diabetes is a leading cause of cardiovascular disease, blindness, kidney failure, and lower limb amputation.

The International Diabetes Federation has estimated that the worldwide prevalence of diabetes mellitus is 
expected to increase from 387 million people in 2014 to 592 million within the next twenty years. Furthermore, 316 million with impaired glucose tolerance are at high risk from the disease, with projections indicating that over 1 billion people will be living with or at high risk of diabetes in 2035 [4]. There were 72.1 million people with diabetes mellitus in the South East Asia region in 2013 and this number is expected to increase to 123.0 million by 2035 . India alone has 65.1 million people living with diabetes mellitus; this places India second to China with 98.41 million diabetic people [5]. Diabetes imposes a large economic burden on the global health-care system and the wider global economy. Diabetes and its complications impose significant economic costs on patients, their families, health systems, and national economies because of direct costs of treatment and loss of work and wages. Based on cost estimates from a recent systematic review, it has been estimated that the direct annual cost of diabetes to the world is more than US\$ 825 billion [6], with China ( $\$ 170$ billion), the USA ( $\$ 105$ billion), India ( $\$ 73$ billion), and Japan ( $\$ 37$ billion) [7]. According to another published in 2005 on 'Global Burden of Neurological Disorders' by WHO, neurological disorders contribute to $10.9,6.7,8.7$ and $4.5 \%$ of the global burden of disease in high, upper-middle, lower-middle and low-income countries, respectively. Moreover, neurological disorders are also an important cause of mortality and this constituted $12 \%$ of total deaths globally [8].

Diabetes has been associated with various comorbid conditions including brain disorders such as depression, anxiety and cognitive dysfunctions. This association is also responsible for other vascular and behavioral complications that might be mediated by brain oxidative stress and neuronal degeneration $[9,10]$. One of the most serious mental health comorbidities associated with diabetes is major depressive disorder. Overall rates of depression among individuals with type- 1 or -2 diabetes is twice more than in general population [11]. Diabetes mellitus is associated with changes in both the blood-brain barrier and transport functions of the cerebral micro-vessels. Structural changes in cerebral microvessels may account for some of the observed changes [12]. Diabetes induces advanced brain aging and may ultimately result in deficits in cognitive performance and increased risk of developing clinical manifestations of Alzheimer's disease (AD) [13, 14]. Furthermore, it has also been reported that $\mathrm{AD}$ and vascular dementia are more frequent in diabetic patients than in non-diabetic persons [15], and that aspects of frontal lobe function, such as psychomotor efficiency, processing speed and executive function, are generally more impaired in diabetics [16]. Insulin resistance mediated impairments in energy metabolism lead to oxidative stress, generation of reactive oxygen species, DNA damage, and mitochondrial dysfunction, all of which drive pro-apoptosis, proinflammatory, and pro-A $\beta \mathrm{PP}-\mathrm{A} \beta$ cascades [17]. Living with diabetes and/or obesity is associated with broad range of distressed lifestyle, such as feeling overwhelmed with diabetic regimen, being concerned with future and the possibility of serious complications, etc. Thus, the combination of distressed lifestyle (which changes neurotransmitter levels) and molecular changes in CNS due to chronic hyperglycemia could be the root cause of psychiatric comorbidities in metabolic syndrome. In most of the animal research on diabetes and cognitive performance, it has been concluded that insulin deficiency may result in impairments in synaptic plasticity and cognitive processes while human studies suggest that insulin insensitivity may affect cognitive processing only [18]. There are ample evidences regarding prominent role played by neurotransmitter acetylcholine in memory function of diabetics Several comorbid conditions have been described in rodent models of diabetes including depression and anxiety [19]. The rate of Generalized Anxiety Disorders and subsyndromal anxiety are higher in diabetic patients [20]. Despite extensive efforts and considerable progress, proper pharmaco-therapeutic managements of comorbid mental health conditions, often associated with almost all chronic health problems including diabetes still remain to be one of the major challenges for medicine [21, 22]. The present review article is focussed on the role of glucose homeostasis and neurotransmitter metabolism in diabetic brain, and the potential use of prebiotics, probiotics and herbal drugs in the management of comorbid conditions associated with diabetes. In addition, we have also highlighted the potentials of CNS acting drug on glucose homeostasis and CNS modulating effects of antidiabetic drug, which might be attractive areas of translational research for drug discovery and development.

\section{Glucose homeostasis and brain functions}

The mammalian brain depends upon glucose as its key source of energy, and tight regulation of glucose metabolism is critical for brain physiology [23]. In the human adult brain, neurons have the highest energy demand [24], requiring continuous delivery of glucose from blood. In human, the brain accounts for approximately $2 \%$ of the body weight, but it consumes approximately $20 \%$ of glucose-derived energy making it the primary consumer of glucose (approximately $5.6 \mathrm{mg}$ glucose per $100 \mathrm{~g}$ human brain tissue per minute) [25]. Glucose metabolism provides the fuel for physiological brain function through the generation of ATP, the foundation for neuronal and non-neuronal cellular maintenance, as well as the generation of neurotransmitters. Glucose is required to provide the precursors for neurotransmitter 
synthesis and the ATP to fuel their actions as well as the brain's energy demands not related to signaling. The largest proportion of energy in the brain is consumed for neuronal computation and information processing [26], e.g. the generation of action potentials and postsynaptic potentials generated after synaptic events, and the maintenance of ion gradients and neuronal resting potential $[24,27]$. Additionally, glucose metabolism provides the energy and precursors for the biosynthesis of neurotransmitters. Importantly, astrocytic glycogen seems to be directly relevant for learning [28]. All brain regions are metabolically active at all times, but there is a large heterogeneity among various brain structures.

Besides hormones and nutrients, both afferent and efferent metabolic signals link hindbrain nuclei and the gastrointestinal tract through the vagal nerve [29]. Thus, a complex interplay between the brain, in particular the hypothalamus, and peripheral systems control glucose supply to the brain, peripheral nutrient uptake $[29,30]$, and utilization, as well as feeding [31-33]. Finally, disrupted central glucose sensing, insulin signaling, and defective hypothalamic circuits have been implicated in the pathophysiological mechanism of type- 2 diabetes mellitus and obesity. At the same time, deregulated glucose metabolism in diabetes mellitus can injure the brain through both hypo- and hyperglycemia [34]. Furthermore, severe complication after cerebral ischemia, has been in part ascribed to dysregulation of the hypothalamus-pituitary-adrenal axis and perturbed efferent signaling [35]. Given the role of hypothalamic structures for glucose and nutrient sensing [29,30], disturbed central glucose level and impeded central regulation of peripheral glucose metabolism may contribute to the development various CNS comorbidities.

\section{Neurotransmitters and CNS complications}

Carbohydrates contain sugar, which is used as nutrition by body metabolizes for energy. Carbohydrates also influence the blood levels of certain amino acids and the synthesis of neurotransmitters, substances in brain that communicate messages between nerve cells and affect mood, appetite and sleep. Functional metabolic activities include so-called 'housekeeping' processes (e.g., macromolecule turnover and axonal transport), biosynthesis of many types of neurotransmitters, signaling within and among cells and maintenance and restoration of membrane potentials [36]. Dietary carbohydrates and proteins affect plasma concentrations of tryptophan and the other large neutral amino acids viz. tyrosine, phenylalanine, leucine, isoleucine, valine, and methionine [37, 38], these macronutrients also affect brain tryptophan concentrations and, thereby, serotonin synthesis and release [39, 40]. Biosynthesis of amino acids, monosaccharide and complex carbohydrates is essential for neurotransmission and macromolecular turnover, and requires the use of glucose as the carbon source. Tryptophan and tyrosine are dietary amino acids vital for synthesis of neurotransmitters, also called monoamines. Tryptophan is the precursor to serotonin and tyrosine is the precursor to dopamine and nor-epinephrine [41]. Glucose metabolism fulfils important functions in adult brain related to neuroenergetics, neurotransmission, energy storage, biosynthesis and oxidative defense. The major energy-producing pathways are glycolysis (glucose to pyruvate) and oxidative metabolism (pyruvate to $\mathrm{CO}_{2}$ ) via the TCA (tricarboxylic acid) cycle and the electron transport chain. Neuromodulators and neurotransmitters must be produced endogenously from substrates derived via these two pathways because passage of neuroactive compounds from blood to brain across the blood-brain barrier is highly restricted [42].

Intercellular communication in the CNS requires the precise control of the duration and the intensity of neurotransmitter action at specific molecular targets. After they have been released at the synapse, neurotransmitters activate pre- and/or postsynaptic receptors. To terminate synaptic transmission, neurotransmitters are, in turn, inactivated by either enzymatic degradation or active transport in neuronal and/or glial cells by neurotransmitter transporters [43]. Once inside the neuronal cell, vesicular carriers can further transport neurotransmitters into synaptic vesicles. These processes are responsible for the homeostasis of neurotransmitter pools within nerve endings [44].

Mainly three monoamine neurotransmitters in the brain viz. dopamine (DA), nor-epinephrine (NE), and serotonin (5-HT) play an important relationship in major depressive disorders. However, specific symptoms are associated with the increase or decrease level of specific neurotransmitters [45]. The first major hypothesis also called as "Monoamine Hypothesis" of depression proposed that the main symptoms of depression are due to a functional deficiency of these brain monoaminergic transmitters $[46,47]$. The most predictable anxiolytic effects of neurotransmitters are linked to the activation of a gamma-aminobutyric acid (GABA)-ergic subsystem associated with specific benzodiazepine receptors [48]. It should nevertheless be recognized that GABA is not the only neurotransmitter important in the modulation of anxiety responses in the amygdala, and many other neurotransmitters have been implicated, including serotonin, opioid peptides, endocannabinoids, neuropeptide Y, oxytocin, and corticotropin-releasing hormone [49].

\section{Diabetes and CNS complications}

Hyperglycemia is a common event among patients with type- 1 and type- 2 diabetes. Over time, diabetes can damage the heart, blood vessels, eyes, kidneys, and nerves. 
Diabetes mellitus also accompanied by numerous structural, behavioral, and biochemical alterations of the central nervous system [50]. Numerous such comorbid conditions are observed in rodent models of diabetes, and exaggerated symptoms of depression, anxiety, and cognitive deficits are observed in diabetic animals [19, 51-56]. Even though depressive symptoms, anxiety and cognitive dysfunctions have been well-established comorbidities in diabetic patients [57], but more attention has been paid to depression only. This might be because available evidences from extensive population studies suggest that the relationship between diabetes and depression is bidirectional [58] and that such is not necessarily the case for diabetes and anxiety or diabetes and memory impairment [59]. However, despite numerous efforts, no definitive statement has been made on the complexity of the cause effect relationship between diabetes (and other metabolic disorders) and diverse types of psychosomatic and/or mood related disorders. Therefore, complex interactions of physical, psychological, and genetic factors that contribute to such associations remain to be properly defined. The relationships between various comorbid CNS conditions in diabetes are summarized in Fig. 1.

\section{Diabetes and depression}

Diabetes and depression are two major chronic diseases with bidirectional relationship, and both of them are spreading like epidemics in almost all countries around the globe [60]. Co-occurrence of these two pathologies in same patients has strong negative impacts on their quality of life and shortens their life span [61, 62]. Depression has been found also to be associated with alterations in diverse other diabetes related psychological and physiological processes [63, 64], and it has been reported that prevalence of depression in diabetics is higher than prevalence of depression in normal population [65]. Numerous structural, behavioural and biochemical alterations of the central nervous system are observed in diabetic patients and such diverse alterations are observed in rodent models of diabetes $[19,50-52,54-56$, 66]. The fact that deregulated oxidative process involving catalase and superoxide dismutase enzyme activity accompanying cognitive psychopathologies in diabetic rats is well established [51, 52,67] and such pathologies influence not only brain functions, but also diverse other biological processes involved in hyperglycemia and other central as well as peripheral pathologies [68]. Although complex interactions of physical, psychological and genetic factors that contribute to such associations remain to be properly defined, available evidence strongly suggest that depression could as well be a consequence of persistent metabolic abnormalities [69, 70]. However, it has been also reported that depression actually doubles the risk of type- 2 diabetes, and that depression could as well be an independent risk factor for type- 2 diabetes [71-73]. It has been observed that the prevalence of depression was significantly higher in patients with type- 2 diabetes compared with those without (17.6 vs. 9.8\%). These prevalence of depression was higher in females with diabetes $(23.8 \%)$ compared with male $(12.8 \%)$ diabetics [74]. Patients with diabetes and depression have

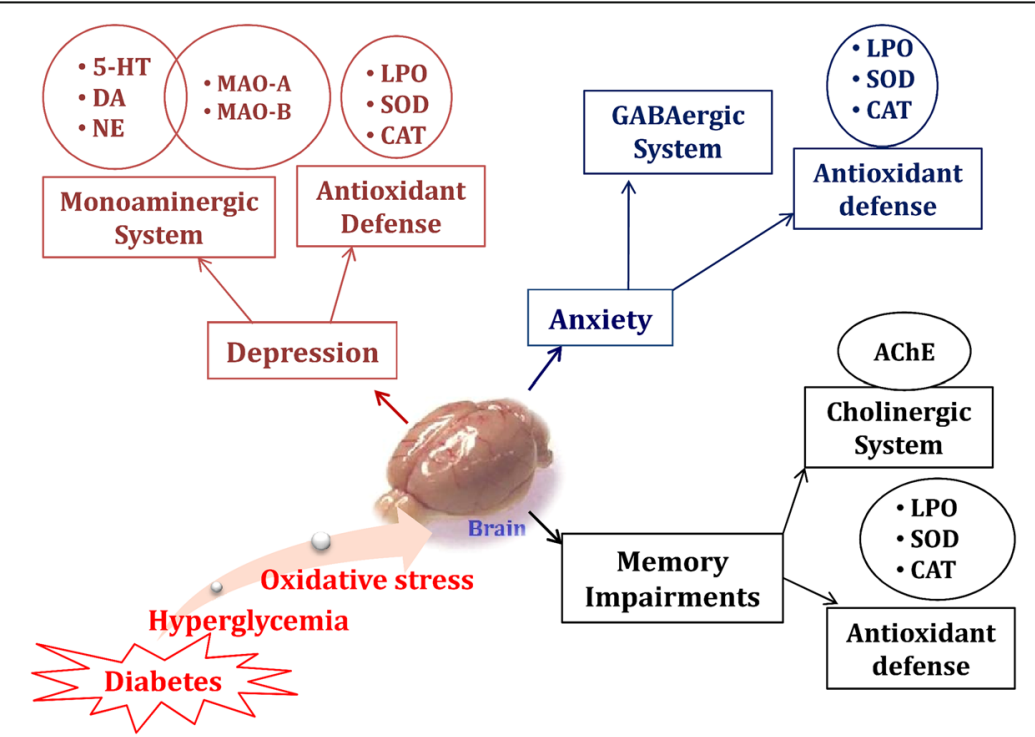

Fig. 1 Comorbid brain disorders associated with diabetes. Oxidative stress and hyperglycemia are responsible for depression, anxiety and memory impairments in diabetes. Imbalances in monoaminergic neurotransmitters and anti-oxidant system are involved in the progression of these complications. Acronyms: 5-HT: 5-Hydroxytryptamine; DA: Dopamine; NE: Nor-epinephrine; MAO-A/B: Monoamine oxidase -A/B; LPO: Lipid Hydroperoxide; SOD: Superoxide dismutase; CAT: Catalase; GABA: Gamma-aminobutyric acid; AChE: Acetylcholinesterase 
been shown to have greater number of risk factors e.g. poor compliance with personal diabetic care (adherence to diet, checking blood sugar level), increased risk of retinopathy and macro-vascular complications, have a decreased quality of life, and increased disability burden [75].

\section{Diabetes and anxiety}

Anxiety is related with emotional aspect of human being, which is universal in nature. Generally, anxiety stimulates and prepare individual to face potential threats and challenges, but its persistent and overwhelming occurrence precipitate pathological conditions known as 'Anxiety Disorders'. Anxiety has also been associated with poor glycemic control seen in diabetic patients. According to a survey based study it was found that compared to rates seen in the general population, the rates of Generalised Anxiety Disorders and subsyndromal anxiety are higher ( $40 \%$ of diabetic patients have elevated levels of anxiety symptoms) in diabetes [20]. In addition, recent clinical studies have shown the prevalence of anxiety in diabetic patients to be much higher than the normal population, supporting the notion that there exists a strong relationship between diabetes and anxiety disorder [76-78]. Anxiety in patients with diabetes is associated with less frequent blood glucose monitoring and suboptimal glycemic control [79], which further worsen the diabetic condition. Previous reports have shown that diabetes results in anxiety-like behaviour in various preclinical testing paradigms. Diabetic rats demonstrated increased time spent in closed arms in elevated plus maze and reduced time spent in central arena in open field test $[54,80]$. Diabetes has also evidenced anxietylike behaviours in rodents subjected to social interaction and zero maze tests [81]. Moreover, decreased exploratory behaviour as less number and duration of head dips has been found in diabetic mice during hole-board test [82]. These suggest that, diabetes significantly develops anxiety-like behaviour and is an effective tool for evaluating neuro-behavioural consequences of diabetes in rodents as well as in screening potential effects of various drug molecules in anxiety-like behaviour associated with diabetes.

Benzodiazepines (BZDs) have been used as the drug of choice for the treatment of anxiety disorders. However, long-term uses of BZDs do have various side effects such as development of tolerance, emergence of withdrawal symptoms and cognitive impairment [83]. Due to these disadvantages associated with use of BZDs, now antidepressants such as SSRIs and SNRIs are being frequently prescribed as first line anxiolytics. The other advantage of using SSRIs as anxiolytic is that they improve both psychic and somatic symptoms of anxiety disorders [84]. An increased adrenergic activity in anxiety has been postulated as main factor behind poor glycemic control. On the other hand hyperglycemia associated with diabetes has also been found to exert anxiogenic effect [85]. Some drugs used to treat anxiety such as alprazolam have been found to have beneficial effects in glycemic control in patients suffering with comorbid anxiety associated with diabetes [86].

\section{Diabetes and memory impairments}

Memory impairment associated with diabetes is also well reported and chances of cognitive dysfunctions and dementia are almost double in diabetic patients [87]. Acute ingestion of high glycemic index carbohydrate foods in diabetic patients has been found to aggravate memory impairment [88]. In contrast, better glycemic control has been found to improve cognitive performance [15, 89]. Brain imaging study in diabetic patients have revealed that changes observed in various brain region follow a similar pattern to that of ageing person's brain features suffering with cognitive decline [90]. Deficits in hippocampal synaptic plasticity observed in diabetes ultimately have deleterious consequences upon cognitive function. A multifaceted role of insulin has been implicated in cognitive performance in normal as well as diabetic individual. Deficits in insulin receptor signalling and impairments in hypothalamic-pituitary-adrenal axis function also contribute to the neurological complications of diabetes phenotypes [91]. Impairment of insulin activity in Alzheimer's disease having dementia as hallmark is well documented in various studies. In most of the animal research on diabetes and cognitive performance, it has been concluded that insulin deficiency may result in impairments in synaptic plasticity and cognitive processes while human studies suggest that insulin insensitivity may affect cognitive process only. Thus, overwhelming evidences from animal and clinical studies suggest functional link between diabetes and cognitive impairment underlying diverse mechanism of action [18]. Streptozotocin (STZ)-induced diabetic rats have been found to display deficits in cognitive tasks, such as performance on the Morris water maze [92]. STZ-induced diabetes in rats results in altered function of NMDA [93] and AMPA [94] type glutamate receptors, which are involved in learning and memory processes. In most of the animal research on diabetes and cognitive performance, it has been concluded that insulin deficiency may result in impairments in synaptic plasticity and cognitive processes while human studies suggest that insulin insensitivity may affect cognitive processing [18]. There are ample evidences regarding prominent role played by neurotransmitter acetylcholine in memory function of animals. At the same time, there is significant and selective degeneration of neurons having cholinergic intervention in hippocampus, cortex and 
hypothalamus of Alzheimer's disease patients [95]. The core strategy to treat dementia of Alzheimer's disease has been to augment the level of acetylcholine by inhibiting the enzyme AChE. Currently the drug available to improve cognition in Alzheimer's disease such as galanthamine, rivastigmine and donepezil are AChE inhibitors [96] but their limited efficacy and peripheral side effects impose a drawback for long time use [97].

\section{Gut-microbiota and brain disorders}

The relationship between the degree of gut health and human disease processes has long been recognized: Hippocrates (460-370 B.C.) stated, "All diseases begin in the gut" [98]. The gut microbiome has played a crucial role in the bidirectional gut-brain axis that integrates the gut and central nervous system (CNS) activities, and thus the concept of microbiome-gut-brain axis is emerging. Evidences are accumulating to suggest that gut-microbiota essentially involved in neural development and function, both peripherally in the enteric nervous system and centrally in the brain. The symbiotic relationship between intestinal microbiota and host ensures appropriate development of the metabolic system in humans [99]. The gastrointestinal tract of a healthy adult hosts around $10^{2}$ microbial cells within the highly acidic environment of the stomach, into the duodenum and jejunum. The distal ileum contains around $10^{7}-10^{8}$ microbial cells with the largest proportion of microbes finally residing in the colon, containing around $10^{11}-10^{12}$ microbial cells [100]. Increasing number of findings suggests the broader role of gut-microbiota in the modulation of various physiological and pathological conditions, and it is now well recognized that a bidirectional communication between brain and gut-microbiota is essential to maintain homeostasis [101-103]. Gut microorganisms are capable of producing and delivering neuroactive substances such as serotonin and gamma-aminobutyric acid, which act on the gut-brain axis [101, 104, 105]. GABA, which is the main inhibitory neurotransmitter in the human brain, is produced by many lactobacilli, and for most babies born per vaginum are the first bacteria to which they are exposed. As mentioned above other essential neurotransmitters such as $5 \mathrm{HT}, \mathrm{NE}$, DA are also produced by microbes [106]. Based on evidence, the gut microbiota is associated with metabolic disorders such as obesity, diabetes mellitus and neuropsychiatric disorders such as schizophrenia, autistic disorders, anxiety disorders and major depressive disorders [103, 107]. In the past few years, neuroscientific research has shown the importance of the microbiota in the development of brain systems. The gut-brain axis includes CNS, the neuroendocrine and neuroimmune systems, autonomic nervous system, enteric nervous system, and intestinal microbiota $[104,108]$.
Concentrations of tryptophan, the precursor of serotonin, are increased in the plasma of male GF animals, suggesting a humoral route through which the microbiota can influence CNS serotonergic neurotransmission. Interestingly, colonization of the germ-free (GF) animals postweaning is insufficient to reverse the CNS neurochemical consequences in adulthood of an absent microbiota in early life despite the peripheral availability of tryptophan being restored to baseline values. In addition, reduced anxiety in GF animals is also normalized following restoration of the intestinal microbiota. According to a study by [109], there were significant increases in tryptophan levels in rats treated with the probiotic Bifidobacerium infantis 35624. This probiotic has been shown to have antidepressant action in preclinical models of depression and may thus constitute a psycho-biotic with a mental health benefit [110]. The relationships between gut-brain axis and mental health along with potential modulating effect of probiotics and prebiotics on neurotransmitters and glucose homeostasis are shown in Fig. 2.

\section{Gut-micobiota and neurotransmitters}

Gut microbiota influences the release of some of the major brain neurotransmitters which act in the gut-brain axis and modulate food intake and energy balance i.e., short chain fatty acids (SCFAs), Peptide YY (PYY), tryptophan, serotonin, endocannabinoid ligands, cholecystokinin, and ghrelin $[107,111]$. GABA is a metabolite

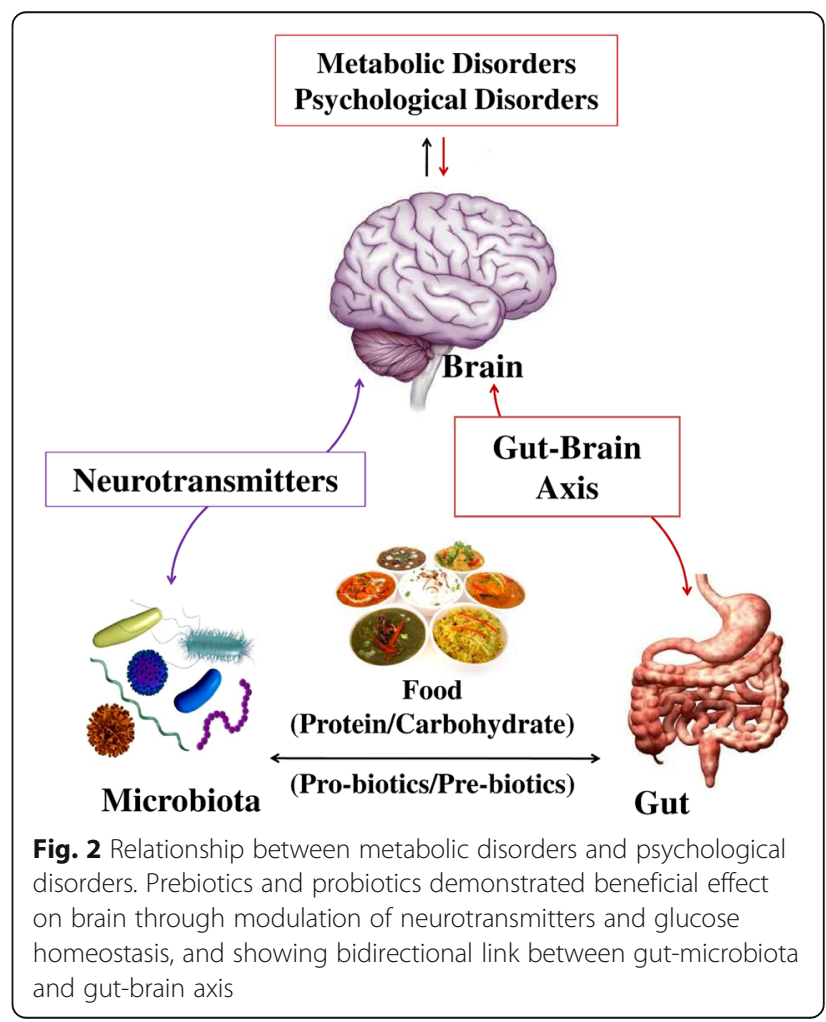


produced from glutamate by the glutamate decarboxylase pathway of many lactic acid bacteria [112]. Serotonergic neurotransmission modulates many brain functions including emotion, cognition, motor function, pain as well as neuroendocrine functions such as food intake, circadian rhythms and reproductive activity. 5HT is an important signaling molecule in the gut-brain axis and the 5-HT released from enterochromaffin cells modulates peristaltic, secretory, vasodilatory, vagal and nociceptive reflexes $[108,113]$. Studies are revealing how diverse forms of neuro-immune and neuro-psychiatric disorders are correlated with or modulated by variations of microbiome, microbiota-derived products and exogenous antibiotics and probiotics. Bacteria have the capacity to generate many neurotransmitters and neuromodulators [103]. Probiotics (i.e., live microorganisms similar to beneficial microorganisms found in the human gut) are reported to modulate a number of disorders including metabolic disorders, behavioral conditions and cognitive functions. It has been recently reviewed that Lactobacillus spp. and Bifidobacterium spp. produce GABA; Escherichia spp., Bacillus spp. and Saccharomyces spp. produce noradrenalin; Candida spp., Streptococcus spp., Escherichia spp. and Enterococcus spp. produce serotonin; Bacillus spp. produce dopamine; and Lactobacillus spp. produce acetylcholine [107, 108]. As the impact of the gut microbiota in complex conditions such as anxiety and depression, and in cognition, is increasingly being recognized and behavior, neurophysiology and neurochemistry can be affected in many ways through modulation of the gut microbiota. Therefore, elucidating the mechanisms by which microbiota communicate with the gut-brain axis will be crucially important for the development of any microbiota-based and microbiotaspecific therapeutic strategies for CNS diseases are urgently required $[107,108]$.

\section{Gut-microbiota and glucose metabolism}

Recent evidence strongly suggests that the gut-microbiota also play an important role in the regulation of energy balance and weight in animals and humans and may influence the development and progression of obesity and other metabolic disorders, including type- 2 diabetes [114-117]. Gut microbial composition and functions are strongly influenced by diet, and affect metabolism via energy absorption, gut motility, appetite, glucose/lipid metabolism, as well as fat storage in the liver. The gut microbiota plays a significant role in the development of the metabolic syndrome and an impairment of gut microbes can cause inflammation and insulin resistance [118]. It has been reported that metabolic pathways are generally affected by the intestinal microbiota, bacterial glycoside hydrolases enzyme cleave complex carbohydrates derived from dietary fiber to produce
SCFAs such as acetate, propionate and butyrate. SCFAs affect the host's metabolism in several ways, for example SCFAs dependent activation of G-protein coupled receptor 41 (Gpcr41) induces the expression of peptide YY, an intestinal hormone that inhibits gut motility, increases intestinal transit rate, and reduces the harvest of energy from the diet [119].

An analysis of population-based study reported that the gut microbiota of the children suffering from type-1 diabetes was different from the gut microbiota of the children without diabetes. Some of the gut microbiota species were also correlated with blood glucose levels in the children with diabetes [120]. The intestinal microbiota is one of these environmental factors recently under study, partly because of observations in both nonobese diabetic mice and BioBreeding diabetes-prone rats, where the use of antibiotics was shown to prevent the onset of diabetes $[120,121]$. On the other hand, supplementation with probiotics in the first month of life successfully reduced the risk of type-1 related autoimmunity in children with high genetic risk of type-1 diabetes [122].

\section{Probiotics, prebiotics and brain functions}

A beneficial microorganism defends the host organisms against the penetration of harmful microorganisms, and has many other functions in the gut wall integrity, innate immunity, insulin sensitivity, metabolism, and it is in cross talk with the brain functions as well. It is a recent recognition, that intestinal microbiota has a direct effect on the brain, and the brain influences the microbiota [105]. The effects of manipulating enteric flora by probiotics (live bacteria given in oral quantities that allow for colonization of the colon) or pre-biotics (nondigestible oligosaccharides like insulin and oligofructose that are fermented by colonic microbiota and enhance the growth of beneficial commensally organisms like Bifidobacterium and Lactobacillus spp.) have been evaluated in several controlled trials [117]. In a recent report it has been demonstrated that probiotics treatment improves diabetes-induced impairment of synaptic activity and cognitive function [123]. This two-way gut-brain axis consists of microbiota, immune and neuroendocrine system, as well as of the autonomic and central nervous system [108, 124]. Compared with the carbohydratealone diet, the pre-biotic with carbohydrate diet increased the intestinal proportion of Lactobacilli and Bifidobacteria, preserved tight junction integrity and intestinal barrier function, and lowered endotoxinemia and systemic and hepatic cytokines and oxidative stress [116]. Now, the evidence of the gut-microbiota influence on behavior and brain chemistry is well-documented [125]. It is also known that normal healthy microbiota influences the development and function of CNS, via 
behavioral and molecular changes [102]. The oral treatment of rats with Lactobacillus reuteri, which activated calcium dependent potassium channels in enteric neurons in the colonic myenteric plexus, proves that that gut microbiota may affect brain via autonomic nervous system [126].

\section{Herbal drugs and brain functions}

In Ayurveda, Rasayana drugs constitute the group of drugs, which have over all beneficial effects on physical and mental health, can be used in a variety of mental disorders [127]. Treatment of CNS complications by modern medicine has several shortcomings. Most medications for brain disorders have strong side effects [128131]. Chances of reoccurrence are also high with treatment of CNS complications by modern medicine [132]. Thus, search for effective and safer medications for comorbid brain disorders are necessary and plant sources can prove to be a better option. During recent years, suggestions have been often made of structurally and functionally diverse secondary plant metabolites as potential therapeutic leads for prevention and cure of diabetes-associated dementia [133-135]. On other hand, numerous phytochemicals cannot only alter gut microbial ecology [136, 137], but also are extensively anabolised and catabolised inside the gastrointestinal tract [138]. It has been demonstrated that the deteriorated memory function observed in diabetic rats was accompanied with elevated acetylcholinesterase activity in their brains, and both these pathologies were dose dependently antagonised by treatments with Andrographis paniculata extract as well as isolated pure Andrographolide. Observed alterations in glucose and insulin level and oxidative status in diabetic rats were also antagonised by both the test agents. Oxidative processes and blood glucose and insulin level regulate central cholinergic functions, which be the reason for their observed memory function improving as well as other CNS activities [52, 53, 139]. In an independent study, it has been reported that Hypericum perforatum significant antidepressant, anxiolytic as well as improvement in memory functions of diabetic rats $[66,140]$. During recent years, implications have often been made that diverse secondary plant metabolites are potential therapeutic leads for management of CNS comorbidities associated with diabetes [133, 141, 142]. Moreover, edible vegetable like Brassica juncea has been reported to be beneficial in cognitive functions and other CNS functions of diabetic rodents by modulating the anti-oxidative enzymes and neurotransmitters activities $[51,56]$.

\section{CNS acting drugs and glucose metabolism}

Persons with psychiatric disorders generally do have multiple risk factors for the development of type-2 diabetes, including physical inactivity and obesity [143]. Stress-induced elevations of glucocorticoids increase glucose concentrations through multiple mechanisms, including synergy with other counter-regulatory hormones to stimulate glycogenolysis, gluconeogenesis, lipolysis, and inhibition of peripheral glucose transport and utilization. Compared to non-depressed controls, depressed subjects display decreased glucose utilization in the left lateral prefrontal cortex, although clinical response to antidepressant treatment is associated with increased glucose metabolism within the cingulate, prefrontal cortex, and/or basal ganglia [144-146]. It has been shown that complex mechanism of blood glucose homeostasis involves several hormonal and non-hormonal components such as serotonin, dopamine and noradrenaline, which affect blood glucose level [147]. In an independent study it has been concluded that plasma glucose levels are under separate serotonergic and dopaminergic control, exerted via $5-\mathrm{HT}_{1 \mathrm{~A}}$ and DA D3 receptors, respectively [148]. Some serotonergic antidepressants (e.g., fluoxetine) reduce hyperglycaemia, normalise glucose homeostasis and increase insulin sensitivity, whereas some noradrenergic antidepressants (e.g., desipramine) and TCAs exert opposite effects and may deteriorate glucose tolerance [149]. However, some dual-mechanism antidepressants (e.g., duloxetine and venlafaxine) do not appear to disrupt glucose homeostatic dynamics, whereas nonselective hydrazine monoamine oxidase inhibitors (e.g., phenelzine) are associated with hypoglycaemia and an increased glucose disposal rate [150]. Many anxiolytics used in diabetes are reported to produce alteration in blood glucose and insulin level. In pre-clinical studies, anxiolytics such as buspirone acting through serotonin receptors $\left(5-\mathrm{HT}_{1}\right.$ receptors) demonstrated altered the plasma glucose and insulin levels [148, 151].

Administration of dopamine agonist drugs modifies glucose metabolism in selected brain areas. Low doses of psychostimulants, which elicit locomotion and exploratory behavior and produce reinforcement, increase glucose metabolism in the limbic system, particularly in the nucleus accumbens [152]. Dopaminergic drugs increase serum insulin probably by interacting with dopaminergic receptors, but stimulation of beta-adrenergic receptors cannot be ruled out [153]. Methylphenidate induced variable changes in brain glucose metabolism, but it consistently increased cerebellar glucose metabolism. It also induced a significant reduction in relative glucose metabolism in the basal ganglia [154]. However, aniracetam, a potent modulator of the glutamatergic and cholinergic systems, prevents glucose metabolic reduction in the cholinergically denervated frontal cortex with little effect on the cortical cholinergic system [155]. Atypical antipsychotic drugs such as Olanzapine, which act on these 
monoamine systems, are implicated in the onset of obesity and diabetes in a substantial number of patients [156]. Animal studies confirm that atypical antipsychotic drugs can cause severe hepatic insulin resistance in the absence of changes in mass of adipose tissue [157]. In mice, the use of dopamine receptor antagonists is associated with weight gain and insulin resistance, whereas agonists of the D1 and D2 dopamine receptor isoforms decrease food intake and improve insulin sensitivity $[158,159]$. Therefore, CNS acting drugs need to be studied for their glucose catabolic and anabolic effects in diabetic patients.

\section{Metformin and brain functions}

Metformin (N-1,1-dimethylbiguanide), is considered to be one of the most effective therapeutics for treating type-2 diabetes because it specifically reduces hepatic gluconeogenesis without increasing insulin secretion. For several decades, metformin has been used to treat patients with type-2 diabetes worldwide, yet the underlying mechanism by which it inhibits hepatic gluconeogenesis until a very recent study in which authors conclusively showed that metformin non-competitively inhibits the redox shuttle enzyme mitochondrial glycerophosphate dehydrogenase [160]. Furthermore, Adenosine-monophosphate-activated protein kinase (AMPK) activation is the most well-known mechanism of metformin action by which it re-sensitizes insulin receptors along with other several beneficial actions [161-163]. However, some of the biological responses to metformin (e.g. the release of cytokines and the expression of Arginase I or PGC- $1 \alpha$ ) are not limited to AMPK activation but also are mediated by AMPK-independent mechanisms [164].

Significantly, it was found that orally-dosed metformin (plasma concentration $13.8 \pm 2.8 \mu \mathrm{mol} / \mathrm{L}$ after $1 \mathrm{~h}$, single dose) rapidly crosses the blood-brain barrier and accumulates in brain $(13.5 \pm 2.3 \mathrm{nmol} / \mathrm{L})$ [165]. LC-MS/MSbased proteomic analysis showed that 41 phosphoproteins were up-regulated and 22 phosphoproteins were down-regulated in the brain of metformin-administrated mice suggesting the direct action of metformin on various targets of central nervous system [166]. Furthermore, beneficial effect (neuroprotective effect in fact) of metformin has also been shown in stroke model where it improved the oxidative stress induced by ischemia and ischemia/reperfusion injuries [167]. The results of recent studies suggest that metformin, in addition to its antihyperglycemic efficacy, may also attenuate neuroinflammation in the CNS [164]. In an independent study, it has been concluded that metformin activated AMPK in macrophages and thereby inhibited biosynthesis of phospholipids as well as neutral lipids and also downregulated the expression of endotoxin (LPS)-induced proinflammatory cytokines and their mediators (iNOS and cyclooxygenase 2). Therefore, metformin may have a possible therapeutic effect for the treatment of multiple sclerosis and other inflammatory diseases [168].

Recently, it has been demonstrated that metformin promotes neurogenesis and enhances spatial memory formation. Normally, an atypical PKC-CBP pathway is essential for the normal genesis of neurons from neural precursors and metformin activates this pathway to promote rodent and human neurogenesis in culture [169, 170]. However, it is also demonstrated that AMPK catalytic activity of metformin is not required for early neural development in vivo over activation of their AMPK activity during metabolic stress impairs neuronal polarization in a mammalian target of rapamycin (mTOR)-dependent manner [171]. Furthermore, metformin attenuates Alzheimer's disease-like (AD) neuropathology in obese, leptin-resistant mice by attenuating the increase of total tau, phospho-tau and activated JNK [172]. Thus, anti-diabetic drugs might be a potential candidate for various $\mathrm{CNS}$ activities and should be pharmacologically evaluated for CNS complications generally associated with diabetic patients.

\section{Concluding remarks}

Global burden of comorbidities of diabetes and other metabolic disorders have been explored and are attracting the potential researchers to explore more in the depth of its complications. As the patho-physiology associated with diabetic comorbidity is complex particularly in the brain, the potential role of suitable pharmacotherapy for treatment of such complications must be properly revealed out. Neurotransmitters metabolism and glucose homeostasis demonstrated directly as well as indirectly effect of prebiotics/probiotics on brain functions and regulated by gut-microbiota. Therefore, symbiotic associations between gut-microbiota and mental health along with homeostasis of glucose metabolism might be a novel target for translational medicinal research for the management of comorbid brain disorders associated with diabetes. Several prebiotics and probiotics as translational medicines have been reported for beneficial effect on brain functions as well as metabolic disorders. Moreover, potential pharmacotherapy in Ayurvedic medicinal system with various medicinal plants and edible herbs are now more prominence for their safety and effectiveness in various metabolic disorders and CNS comorbid conditions. Therefore, translational research can be used for better understanding of the relationship between brain glucose homeostasis and CNS complication. This will provide as insight on the modulating effects of poly-pharmacologically active therapeutic agents for comorbid conditions associated with diabetes. 


\section{Abbreviations}

5-HT: 5-Hydroxy Tryptamine; AChE: Acetylcholinesterase; AD: Alzheimer's disease; AMPK: Adenosine-monophosphate-activated protein kinase; BZDs: Benzodiazepines; CNS: Central Nervous System; DA: Dopamine; GABA: gamma-aminobutyric acid; GF: Germ-free; Gpcr41: G-Protein Coupled Receptor 41; NE: Nor-epinephrine; NMDA: N-Methyl-D-aspartic acid; PYY: Peptide YY; SCFAs: Short chain fatty acids; SSRIs: Selective serotonin reuptake inhibitors; STZ: Streptozotocin; TCA: Tricarboxylic acid; WHO: World Health Organization

\section{Acknowledgements}

Not applicable.

\section{Declarations}

Data sharing not applicable to this article as no datasets were generated or analysed during the current study.

\section{Authors' contributions}

The review article was envisaged by AKT and performed literature search. ST and NS are equal contributor in drafting the manuscript. All authors read and approved the final manuscript.

\section{Funding}

No funding source is available

\section{Ethics approval and consent to participate}

Not applicable.

\section{Consent for publication}

Not applicable.

\section{Competing interests}

The authors declare that they have no competing interests.

Received: 29 March 2019 Accepted: 9 July 2019

Published online: 19 July 2019

\section{References}

1. Tao Z, Shi A, Zhao J. Epidemiological perspectives of diabetes. Cell Biochem Biophys. 2015;73(1):181-5.

2. Lallukka T, Ervasti J, Mittendorfer-Rutz E, et al. The joint contribution of diabetes and work disability to premature death during working age: a population-based study in Sweden. Scand J Public Health. 2016:44(6):580-6.

3. Anonymus. Global Report on Diabetes. Geneva: World Health Organization; 2016.

4. da Rocha Fernandes J, Ogurtsova K, Linnenkamp U, et al. IDF Diabetes Atlas estimates of 2014 global health expenditures on diabetes. Diabetes Res Clin Pract. 2016;117:48-54. https://www.diabetesresearchclinicalpractice.com/ article/S0168-8227(16)30080-8/fulltext.

5. Anonymus. The Diabetes Atlas by International Diabetes Federation: International Diabetes Federation; 2013. https://www.idf.org/component/ attachments/attachments.html?id=813\&task=download.

6. Anonymus. Worldwide trends in diabetes since 1980: a pooled analysis of 751 population-based studies with 4.4 million participants. Lancet. 2016;387(10027): 1513-30.

7. Seuring T, Archangelidi O, Suhrcke M. The economic costs of type 2 diabetes: a global systematic review. Pharmacoeconomics. 2015;33(8):811-31.

8. Anonymus. Global burden of neurological disorders estimates and projections. Neurological Disorders: Public Health Challenges: World Health Organization; 2006. p. 27-39. http://www.who.int/mental_health/neurology/ chapter_2_neuro_disorders_public_h_challenges.pdf?ua=1:

9. Mazloom Z, Ekramzadeh M, Hejazi N. Efficacy of supplementary vitamins C and E on anxiety, depression and stress in type 2 diabetic patients: a randomized, single-blind, placebo-controlled trial. Pak J Biol Sci. 2013;16(22):1597-600.

10. Butterfield DA, Di Domenico F, Barone E. Elevated risk of type 2 diabetes for development of Alzheimer disease: a key role for oxidative stress in brain. Biochim Biophys Acta. 2014;1842(9):1693-706.

11. Ducat L, Philipson LH, Anderson BJ. The mental health comorbidities of diabetes. JAMA. 2014;312(7):691-2.

12. Mooradian AD. Central nervous system complications of diabetes mellitus--a perspective from the blood-brain barrier. Brain Res Brain Res Rev. 1997;23(3): 210-8.
13. Gispen WH, Biessels GJ. Cognition and synaptic plasticity in diabetes mellitus. Trends Neurosci. 2000;23(11):542-9.

14. Biessels GJ, van der Heide LP, Kamal A, Bleys RL, Gispen WH. Ageing and diabetes: implications for brain function. Eur J Pharmacol. 2002;441(1-2):1-14.

15. Biessels GJ, Kerssen A, de Haan EH, Kappelle LJ. Cognitive dysfunction and diabetes: implications for primary care. Prim Care Diabetes. 2007;1(4):187-93.

16. Christman AL, Matsushita K, Gottesman RF, et al. Glycated haemoglobin and cognitive decline: the atherosclerosis risk in communities (ARIC) study. Diabetologia. 2011;54(7):1645-52.

17. Lannert $\mathrm{H}$, Hoyer $\mathrm{S}$. Intracerebroventricular administration of streptozotocin causes long-term diminutions in learning and memory abilities and in cerebral energy metabolism in adult rats. Behav Neurosci. 1998;112(5):1199-208.

18. Park CR. Cognitive effects of insulin in the central nervous system. Neurosci Biobehav Rev. 2001;25(4):311-23.

19. Rowland NE, Bellush LL. Diabetes mellitus: stress, neurochemistry and behavior. Neurosci Biobehav Rev. 1989;13(4):199-206.

20. Grigsby AB, Anderson RJ, Freedland KE, Clouse RE, Lustman PJ. Prevalence of anxiety in adults with diabetes: a systematic review. J Psychosom Res. 2002;53(6):1053-60.

21. Ban TA. Pharmacotherapy of mental illness--a historical analysis. Prog NeuroPsychopharmacol Biol Psychiatry. 2001;25(4):709-27.

22. Detweiler-Bedell JB, Friedman MA, Leventhal H, Miller IW, Leventhal EA. Integrating co-morbid depression and chronic physical disease management: identifying and resolving failures in self-regulation. Clin Psychol Rev. 2008;28(8):1426-46.

23. Mergenthaler $P$, Lindauer $U$, Dienel GA, Meisel A. Sugar for the brain: the role of glucose in physiological and pathological brain function. Trends Neurosci. 2013;36(10):587-97.

24. Howarth C, Gleeson P, Attwell D. Updated energy budgets for neural computation in the neocortex and cerebellum. J Cereb Blood Flow Metab. 2012;32(7):1222-32.

25. Erbsloh F, Bernsmeier A, Hillesheim $\mathrm{H}$. The glucose consumption of the brain \& its dependence on the liver. Arch Psychiatr Nervenkr Z Gesamte Neurol Psychiatr. 1958;196(6):611-26.

26. Harris JJ, Jolivet R, Attwell D. Synaptic energy use and supply. Neuron. 2012; 75(5):762-77.

27. Ivannikov MV, Sugimori M, Llinas RR. Calcium clearance and its energy requirements in cerebellar neurons. Cell Calcium. 2010;47(6):507-13.

28. Hertz L, Gibbs ME. What learning in day-old chickens can teach a neurochemist: focus on astrocyte metabolism. J Neurochem. 2009;109(Suppl 1):10-6.

29. Grill HJ, Hayes MR. Hindbrain neurons as an essential hub in the neuroanatomically distributed control of energy balance. Cell Metab. 2012; 16(3):296-309.

30. Lam CK, Chari M, Lam TK. CNS regulation of glucose homeostasis. Physiology (Bethesda). 2009;24:159-70.

31. Joly-Amado A, Denis RG, Castel J, et al. Hypothalamic AgRP-neurons control peripheral substrate utilization and nutrient partitioning. EMBO J. 2012; 31(22):4276-88.

32. Aponte $Y$, Atasoy D, Sternson SM. AGRP neurons are sufficient to orchestrate feeding behavior rapidly and without training. Nat Neurosci. 2011;14(3):351-5.

33. Wu Q, Boyle MP, Palmiter RD. Loss of GABAergic signaling by AgRP neurons to the parabrachial nucleus leads to starvation. Cell. 2009;137(7):1225-34.

34. Scheen AJ. Central nervous system: a conductor orchestrating metabolic regulations harmed by both hyperglycaemia and hypoglycaemia. Diabetes Metab. 2010;36(Suppl 3):S31-8.

35. Scherbakov N, Dirnagl U, Doehner W. Body weight after stroke: lessons from the obesity paradox. Stroke. 2011;42(12):3646-50.

36. Fernstrom JD. Diet-induced changes in plasma amino acid pattern: effects on the brain uptake of large neutral amino acids, and on brain serotonin synthesis. J Neural Transm Suppl. 1979;(15):55-67.

37. Fernstrom JD, Wurtman RJ, Hammarstrom-Wiklund B, et al. Diurnal variations in plasma neutral amino acid concentrations among patients with cirrhosis: effect of dietary protein. Am J Clin Nutr. 1979;32(9):1923-33.

38. Maher TJ, Glaeser BS, Wurtman RJ. Diurnal variations in plasma concentrations of basic and neutral amino acids and in red cell concentrations of aspartate and glutamate: effects of dietary protein intake. Am J Clin Nutr. 1984;39(5):722-9.

39. Schaechter JD, Wurtman RJ. Tryptophan availability modulates serotonin release from rat hypothalamic slices. J Neurochem. 1989;53(6):1925-33. 
40. Schaechter JD, Wurtman RJ. Serotonin release varies with brain tryptophan levels. Brain Res. 1990;532(1-2):203-10.

41. Fernstrom JD, Fernstrom MH. Tyrosine, phenylalanine, and catecholamine synthesis and function in the brain. J Nutr. 2007;137(6 Suppl 1):1539S-47S discussion $48 \mathrm{~S}$.

42. Dienel GA. Fueling and imaging brain activation. ASN Neuro. 2012;4(5):267321. https://journals.sagepub.com/doi/10.1042/AN20120021.

43. Suudhof TC. Neurotransmitter Release. In: Südhof TC, Starke K, editors. Pharmacology of Neurotransmitter Release. Berlin: Springer Berlin Heidelberg; 2008. p. 1-21. https://doi.org/10.1007/978-3-540-74805-2_1.

44. Iversen LL. The uptake of catechol amines at high perfusion concentrations in the rat isolated heart: a novel catechol amine uptake process. $\mathrm{Br} J$ Pharmacol. 1997;120(S1):264-6.

45. Nutt DJ. Relationship of neurotransmitters to the symptoms of major depressive disorder. J Clin Psychiatry. 2008;69(Suppl E1):4-7.

46. Schildkraut JJ. The catecholamine hypothesis of affective disorders: a review of supporting evidence. Am J Psychiatry. 1965;122(5):509-22.

47. Brigitta B. Pathophysiology of depression and mechanisms of treatment. Dialogues Clin Neurosci. 2002;4(1):7-20.

48. Hoehn-Saric R. Neurotransmitters in anxiety. Arch Gen Psychiatry. 1982;39(6): 735-42.

49. Nuss P. Anxiety disorders and GABA neurotransmission: a disturbance of modulation. Neuropsychiatr Dis Treat. 2015;11:165-75.

50. Hilakivi-Clarke LA, Wozniak KM, Durcan MJ, Linnoila M. Behavior of streptozotocin-diabetic mice in tests of exploration, locomotion, anxiety, depression and aggression. Physiol Behav. 1990;48(3):429-33.

51. Thakur AK, Chatterjee SS, Kumar V. Beneficial effects of Brassica juncea on cognitive functions in rats. Pharm Biol. 2013;51(10):1304-10.

52. Thakur AK, Rai G, Chatterjee SS, Kumar V. Beneficial effects of an Andrographis paniculata extract and andrographolide on cognitive functions in streptozotocin-induced diabetic rats. Pharm Biol. 2016. https://doi.org/1 0.3109/13880209.2015.1107107:1-11.

53. Radhika P, Annapurna A, Rao SN. Immunostimulant, cerebroprotective \& nootropic activities of Andrographis paniculata leaves extract in normal \& type 2 diabetic rats. Indian J Med Res. 2012;135(5):636-41.

54. Thakur AK, Chatterjee SS, Kumar V. Anxiolytic-like activity of leaf extract of traditionally used Indian-mustard. TANG (Humanitas Medicine). 2013;3(1):7-1.

55. Thakur AK, Chatterjee SS, Kumar V. Antidepressant-like activity of Andrographis paniculata in type-2 diabetic rats. Clin Pharmacol Biopharm. 2014;\$2(3):1-9.

56. Thakur AK, Chatterjee SS, Kumar V. Antidepressant-like effects of Brassica juncea L. leaves in diabetic rodents. Indian J Exp Biol. 2014;52(6):613-22.

57. Pouwer F. Should we screen for emotional distress in type 2 diabetes mellitus? Nat Rev Endocrinol. 2009;5(12):665-71.

58. Golden SH, Lazo M, Carnethon M, et al. Examining a bidirectional association between depressive symptoms and diabetes. Jama. 2008; 299(23):2751-9.

59. Bouwman V, Adriaanse MC, van't Riet E, et al. Depression, anxiety and glucose metabolism in the general dutch population: the new Hoorn study. PLoS One. 2010;5(4):e9971.

60. Lin EH, Rutter CM, Katon W, et al. Depression and advanced complications of diabetes: a prospective cohort study. Diabetes Care. 2010;33(2):264-9.

61. Dirmaier J, Watzke $B$, Koch $U$, et al. Diabetes in primary care: prospective associations between depression, nonadherence and glycemic control. Psychother Psychosom. 2010;79(3):172-8.

62. Roy T, Lloyd CE, Pouwer F, Holt RI, Sartorius N. Screening tools used for measuring depression among people with type 1 and type 2 diabetes: a systematic review. Diabet Med. 2012;29(2):164-75.

63. de Groot M, Anderson R, Freedland KE, Clouse RE, Lustman PJ. Association of depression and diabetes complications: a meta-analysis. Psychosom Med. 2001;63(4):619-30

64. Lustman PJ, Anderson R, Freedland KE, et al. Depression and poor glycemic control: a meta-analytic review of the literature. Diabetes Care. 2000;23(7):934-42.

65. Anderson RJ, Freedland KE, Clouse RE, Lustman PJ. The prevalence of comorbid depression in adults with diabetes: a meta-analysis. Diabetes Care. 2001;24(6):1069-78.

66. Husain GM, Chatterjee SS, Singh PN, Kumar V. Beneficial effect of Hypericum perforatum on depression and anxiety in a type 2 diabetic rat model. Acta Pol Pharm. 2011;68(6):913-8.

67. Ceretta LB, Reus GZ, Abelaira HM, et al. Increased oxidative stress and imbalance in antioxidant enzymes in the brains of alloxan-induced diabetic rats. Exp Diabetes Res. 2012;2012:302682.
68. Maritim AC, Sanders RA, Watkins JB 3rd. Diabetes, oxidative stress, and antioxidants: a review. J Biochem Mol Toxicol. 2003;17(1):24-38.

69. MacKenzie RG, Trulson ME. Effects of insulin and streptozotocin-induced diabetes on brain tryptophan and serotonin metabolism in rats. Neurochem. 1978;30(1):205-11.

70. Trulson ME, Himmel CD. Effects of insulin and streptozotocin-induced diabetes on brain norepinephrine metabolism in rats. J Neurochem. 1985; 44(6):1873-6.

71. Eaton WW, Armenian H, Gallo J, Pratt L, Ford DE. Depression and risk for onset of type II diabetes. A prospective population-based study. Diabetes Care. 1996;19(10):1097-102.

72. Kawakami N, Takatsuka N, Shimizu H, Ishibashi H. Depressive symptoms and occurrence of type 2 diabetes among Japanese men. Diabetes Care. 1999; 22(7):1071-6.

73. Nouwen A, Winkley K, Twisk J, et al. Type 2 diabetes mellitus as a risk factor for the onset of depression: a systematic review and meta-analysis. Diabetologia. 2010;53(12):2480-6.

74. Ali S, Stone MA, Peters JL, Davies MJ, Khunti K. The prevalence of co-morbid depression in adults with type 2 diabetes: a systematic review and metaanalysis. Diabet Med. 2006;23(11):1165-73.

75. Aina Y, Susman JL. Understanding comorbidity with depression and anxiety disorders. J Am Osteopath Assoc. 2006;106(5 Suppl 2):S9-14.

76. Clavijo M, Carvalho JJ, Rios M, de Oliveira IR. Psychiatric disorders in patients with diabetes type 2 at medical care and training district of Rio Branco-acre, Brazil. Arq Neuropsiquiatr. 2006;64(3B):807-13.

77. Herzer M, Hood KK. Anxiety symptoms in adolescents with type 1 diabetes: association with blood glucose monitoring and glycemic control. J Pediatr Psychol. 2010;35(4):415-25.

78. Lin EH, Korff MV, Alonso J, et al. Mental disorders among persons with diabetes--results from the world mental health surveys. J Psychosom Res. 2008;65(6):571-80

79. Shaban MC, Fosbury J, Kerr D, Cavan DA. The prevalence of depression and anxiety in adults with type 1 diabetes. Diabet Med. 2006;23(12):1381-4.

80. Aksu I, Ates M, Baykara B, et al. Anxiety correlates to decreased blood and prefrontal cortex IGF-1 levels in streptozotocin induced diabetes. Neurosci Lett. 2012;531(2):176-81.

81. Ramanathan M, Jaiswal AK, Bhattacharya SK. Differential effects of diazepam on anxiety in streptozotocin induced diabetic and non-diabetic rats. Psychopharmacology. 1998;135(4):361-7.

82. Kamei J, Ohsawa M, Tsuji M, Takeda H, Matsumiya T. Modification of the effects of benzodiazepines on the exploratory behaviors of mice on a holeboard by diabetes. Jpn J Pharmacol. 2001;86(1):47-54.

83. Papp LA, Gorenstein EE, Mohlman J. Treatment of late-life anxiety disorder. In: Simpson HB, Neria Y, Fernandez RL, Schneier F, editors. Anxiety disorders, theory, research and clinical perspective. New York: Cambridge University Press; 2010. p. 297-305.

84. Davidson JR, Bose A, Wang Q. Safety and efficacy of escitalopram in the long-term treatment of generalized anxiety disorder. J Clin Psychiatry. 2005;66(11):1441-6.

85. Lustman PJ, Skor DA, Carney RM, Santiago JV, Cryer PE. Stress and diabetic control. Lancet. 1983;1 (8324):588.

86. Lustman PJ, Griffith LS, Clouse RE, et al. Effects of alprazolam on glucose regulation in diabetes. Results of double-blind, placebo-controlled trial. Diabetes Care. 1995;18(8):1133-9.

87. Leibson CL, Rocca WA, Hanson VA, et al. Risk of dementia among persons with diabetes mellitus: a population-based cohort study. Am J Epidemiol. 1997;145(4):301-8

88. Greenwood CE, Kaplan RJ, Hebblethwaite S, Jenkins DJ. Carbohydrateinduced memory impairment in adults with type 2 diabetes. Diabetes Care. 2003:26(7):1961-6.

89. Strachan MW, Deary IJ, Ewing FM, Frier BM. Is type II diabetes associated with an increased risk of cognitive dysfunction? A critical review of published studies. Diabetes Care. 1997:20(3):438-45.

90. Biessels GJ. Cognition in type 2 diabetes: brain imaging correlates and vascular and metabolic risk factors. In: Craft S, Christen Y, editors. Diabetes, insulin and Alzheimer's disease, research and perspectives in Alzheimer's disease. Heidelberg: Springer-Verlag; 2010. p. 81-8.

91. Reagan LP. Insulin signaling effects on memory and mood. Curr Opin Pharmacol. 2007;7(6):633-7.

92. Kamal A, Biessels GJ, Duis SE, Gispen WH. Learning and hippocampal synaptic plasticity in streptozotocin-diabetic rats: interaction of diabetes and ageing. Diabetologia. 2000;43(4):500-6. 
93. Di Luca M, Ruts L, Gardoni F, et al. NMDA receptor subunits are modified transcriptionally and post-translationally in the brain of streptozotocindiabetic rats. Diabetologia. 1999;42(6):693-701.

94. Chabot C, Massicotte G, Milot M, Trudeau F, Gagne J. Impaired modulation of AMPA receptors by calcium-dependent processes in streptozotocininduced diabetic rats. Brain Res. 1997;768(1-2):249-56.

95. Mufson EJ, Counts SE, Perez SE, Ginsberg SD. Cholinergic system during the progression of Alzheimer's disease: therapeutic implications. Expert Rev Neurother. 2008;8(11):1703-18.

96. Figueiro $\mathrm{M}$, llha J, Pochmann $\mathrm{D}$, et al. Acetylcholinesterase inhibition in cognition-relevant brain areas of mice treated with a nootropic Amazonian herbal (Marapuama). Phytomedicine. 2010;17(12):956-62.

97. Birks J, Flicker L. Donepezil for mild cognitive impairment. Cochrane Database Syst Rev. 2006. https://doi.org/10.1002/14651858.CD006104(3): CD006104.

98. Holmes E, Li JV, Marchesi JR, Nicholson JK. Gut microbiota composition and activity in relation to host metabolic phenotype and disease risk. Cell Metab. 2012;16(5):559-64.

99. Stadler BM, Hirai K, Brantschen S, Nakajima K, de Weck AL. Biochemical characterization of the human basophil-promoting activity. Int Arch Allergy Appl Immunol. 1987;82(3-4):338-40.

100. Patterson E, Ryan PM, Cryan JF, et al. Gut microbiota, obesity and diabetes. Postgrad Med J. 2016. https://doi.org/10.1136/postgradmedj-2015-133285.

101. Carabotti M, Scirocco A, Maselli MA, Severi C. The gut-brain axis: interactions between enteric microbiota, central and enteric nervous systems. Ann Gastroenterol. 2015;28(2):203-9.

102. Diaz Heijtz R, Wang S, Anuar F, et al. Normal gut microbiota modulates brain development and behavior. Proc Natl Acad Sci U S A. 2011;108(7): 3047-52.

103. Wang $Y$, Kasper $L H$. The role of microbiome in central nervous system disorders. Brain Behav Immun. 2014;38:1-12.

104. Evrensel A, Ceylan ME. The gut-brain Axis: the missing link in depression. Clin Psychopharmacol Neurosci. 2015;13(3):239-44.

105. Collins SM, Surette M, Bercik P. The interplay between the intestinal microbiota and the brain. Nat Rev Microbiol. 2012;10(11):735-42.

106. Dinan TG, Stilling RM, Stanton C, Cryan JF. Collective unconscious: how gut microbes shape human behavior. J Psychiatr Res. 2015;63:1-9.

107. Cryan JF, Dinan TG. Mind-altering microorganisms: the impact of the gut microbiota on brain and behaviour. Nat Rev Neurosci. 2012;13(10):701-12.

108. Thakur AK, Shakya A, Husain GM, Emerald M, Kumar V. Gut-microbiota and mental health: current and future perspectives. J Pharmacol Clin Toxicol. 2014;2(1):1-15.

109. Desbonnet L, Garrett L, Clarke G, Bienenstock J, Dinan TG. The probiotic Bifidobacteria infantis: an assessment of potential antidepressant properties in the rat. J Psychiatr Res. 2008:43(2):164-74.

110. Dinan TG, Stanton C, Cryan JF. Psychobiotics: a novel class of psychotropic. Biol Psychiatry. 2013;74(10):720-6.

111. Burokas A, Moloney RD, Dinan TG, Cryan JF. Microbiota regulation of the mammalian gut-brain axis. Adv Appl Microbiol. 2015;91:1-62.

112. Barrett E, Ross RP, O'Toole PW, Fitzgerald GF, Stanton C. Gammaaminobutyric acid production by culturable bacteria from the human intestine. J Appl Microbiol. 2012;113(2):411-7.

113. Crowell MD, Wessinger SB. 5-HT and the brain-gut axis: opportunities for pharmacologic intervention. Expert Opin Investig Drugs. 2007;16(6):761-5.

114. DiBaise JK, Frank DN, Mathur R. Impact of the gut microbiota on the development of obesity: current concepts. Am J Gastroenterol Suppl. 2012; 1(1):22-7.

115. Ley RE, Turnbaugh PJ, Klein S, Gordon Jl. Microbial ecology: human gut microbes associated with obesity. Nature. 2006:444(7122):1022-3.

116. Cani PD, Bibiloni R, Knauf $C$, et al. Changes in gut microbiota control metabolic endotoxemia-induced inflammation in high-fat diet-induced obesity and diabetes in mice. Diabetes. 2008:57(6):1470-81.

117. Cani PD, Neyrinck AM, Fava F, et al. Selective increases of bifidobacteria in gut microflora improve high-fat-diet-induced diabetes in mice through a mechanism associated with endotoxaemia. Diabetologia. 2007:50(11):2374-83.

118. Festi D, Schiumerini R, Eusebi LH, et al. Gut microbiota and metabolic syndrome. World J Gastroenterol. 2014;20(43):16079-94.

119. Tolhurst G, Heffron H, Lam YS, et al. Short-chain fatty acids stimulate glucagon-like peptide-1 secretion via the G-protein-coupled receptor FFAR2. Diabetes. 2012;61 (2):364-71.
120. Murri M, Leiva I, Gomez-Zumaquero JM, et al. Gut microbiota in children with type 1 diabetes differs from that in healthy children: a case-control study. BMC Med. 2013;11:46.

121. Brugman S, Klatter FA, Visser JT, et al. Antibiotic treatment partially protects against type 1 diabetes in the bio-breeding diabetes-prone rat. Is the gut flora involved in the development of type 1 diabetes? Diabetologia. 2006; 49(9):2105-8

122. Uusitalo U, Liu X, Yang J, et al. Association of Early Exposure of probiotics and islet autoimmunity in the TEDDY study. JAMA Pediatr. 2016;170(1):20-8.

123. Davari S, Talaei SA, Alaei H, Salami M. Probiotics treatment improves diabetes-induced impairment of synaptic activity and cognitive function: behavioral and electrophysiological proofs for microbiome-gut-brain axis. Neuroscience. 2013;240:287-96.

124. Halmos T, Suba I. Physiological patterns of intestinal microbiota. The role of dysbacteriosis in obesity, insulin resistance, diabetes and metabolic syndrome. Orv Hetil. 2016;157(1):13-22.

125. Sudo N, Chida Y, Aiba Y, et al. Postnatal microbial colonization programs the hypothalamic-pituitary-adrenal system for stress response in mice. J Physiol. 2004;558(Pt 1):263-75.

126. Kunze WA, Mao YK, Wang B, et al. Lactobacillus reuteri enhances excitability of colonic AH neurons by inhibiting calcium-dependent potassium channel opening. J Cell Mol Med. 2009;13(8B):2261-70.

127. Chatterjee SS, Kumar V. Holistic psychopharmacology and promiscuous plants and principles of Ayurveda. Am J Plant Sci. 2012;3(7A):1015-21.

128. Fisher A, Davis M, Croft-Baker J, Purcell P, McLean A. Citalopram-induced severe hyponatraemia with coma and seizure. Case report with literature and spontaneous reports review. Adverse Drug React Toxicol Rev. 2002; 21(4):179-87.

129. Glassman AH, Roose SP, Bigger JT Jr. The safety of tricyclic antidepressants in cardiac patients. Risk-benefit reconsidered JAMA. 1993;269(20):2673-5.

130. Hamilton MS, Opler LA. Akathisia, suicidality, and fluoxetine. J Clin Psychiatry. 1992:53(11):401-6.

131. Johnston JA, Lineberry CG, Ascher JA, et al. A 102-center prospective study of seizure in association with bupropion. J Clin Psychiatry. 1991;52(11):450-6.

132. Viguera AC, Baldessarini RJ, Friedberg J. Discontinuing antidepressant treatment in major depression. Harv Rev Psychiatry. 1998:5(6):293-306.

133. Davinelli S, Sapere N, Zella D, et al. Pleiotropic protective effects of phytochemicals in Alzheimer's disease. Oxidative Med Cell Longev. 2012; 2012:386527.

134. Apetz N, Munch G, Govindaraghavan S, Gyengesi E. Natural compounds and plant extracts as therapeutics against chronic inflammation in Alzheimer's disease--a translational perspective. CNS Neurol Disord Drug Targets. 2014;13(7):1175-91.

135. Recio MC, Andujar I, Rios JL. Anti-inflammatory agents from plants: progress and potential. Curr Med Chem. 2012;19(14):2088-103.

136. Abreu AC, McBain AJ, Simoes M. Plants as sources of new antimicrobials and resistance-modifying agents. Nat Prod Rep. 2012;29(9):1007-21.

137. Borges A, Saavedra MJ, Simoes M. Insights on antimicrobial resistance, biofilms and the use of phytochemicals as new antimicrobial agents. Curr Med Chem. 2015;22(21):2590-614.

138. Laparra JM, Sanz Y. Interactions of gut microbiota with functional food components and nutraceuticals. Pharmacol Res. 2010;61(3):219-25.

139. Thakur AK, Chatterjee SS, Kumar V. Neuropsychopharmacology of a therapeutically used Andrographis paniculata extract: a preclinical study. Orient Pharm Exp Med. 2014;14(2):181-91.

140. Hasanein P, Shahidi S. Effects of Hypericum perforatum extract on diabetesinduced learning and memory impairment in rats. Phytother Res. 2011;25(4):544-9.

141. Bhutada P, Mundhada Y, Bansod K, et al. Ameliorative effect of quercetin on memory dysfunction in streptozotocin-induced diabetic rats. Neurobiol Learn Mem. 2010;94(3):293-302.

142. Bhutada P, Mundhada Y, Bansod K, et al. Protection of cholinergic and antioxidant system contributes to the effect of berberine ameliorating memory dysfunction in rat model of streptozotocin-induced diabetes. Behav Brain Res. 2011;220(1):30-41.

143. Hayward C. Psychiatric illness and cardiovascular disease risk. Epidemiol Rev. 1995;17(1):129-38

144. Hurwitz TA, Clark C, Murphy E, et al. Regional cerebral glucose metabolism in major depressive disorder. Can J Psychiatr. 1990;35(8):684-8.

145. Baxter LR Jr, Schwartz JM, Phelps ME, et al. Reduction of prefrontal cortex glucose metabolism common to three types of depression. Arch Gen Psychiatry. 1989;46(3):243-50. 
146. Musselman DL, Betan E, Larsen H, Phillips LS. Relationship of depression to diabetes types 1 and 2: epidemiology, biology, and treatment. Biol Psychiatry. 2003;54(3):317-29.

147. Nonogaki K, Iguchi A. Role of central neural mechanisms in the regulation of hepatic glucose metabolism. Life Sci. 1997;60(11):797-807.

148. Uvnas-Moberg K, Ahlenius S, Alster P, Hillegaart V. Effects of selective serotonin and dopamine agonists on plasma levels of glucose, insulin and glucagon in the rat. Neuroendocrinol. 1996;63(3):269-74.

149. Deuschle M. Effects of antidepressants on glucose metabolism and diabetes mellitus type 2 in adults. Curr Opin Psychiatry. 2013;26(1):60-5.

150. McIntyre RS, Soczynska JK, Konarski JZ, Kennedy SH. The effect of antidepressants on glucose homeostasis and insulin sensitivity: synthesis and mechanisms. Expert Opin Drug Saf. 2006;5(1):157-68.

151. Ojha SK, Nandave M, Sharma C. Effect of buspirone: an anxiolytic drug on blood glucose in humans. Indian J Clin Biochem. 2006;21(2):58-62.

152. Orzi F, Morelli M, Fieschi C, Pontieri FE. Metabolic mapping of the pharmacological and toxicological effects of dopaminergic drugs in experimental animals. Cerebrovasc Brain Metab Rev. 1993;5(2):95-121.

153. Contreras F, Foullioux C, Pacheco B, et al. Effect of drugs interacting with the dopaminergic receptors on glucose levels and insulin release in healthy and type 2 diabetic subjects. Am J Ther. 2008;15(4):397-402.

154. Volkow ND, Wang GJ, Fowler JS, et al. Effects of methylphenidate on regional brain glucose metabolism in humans: relationship to dopamine D2 receptors. Am J Psychiatry. 1997;154(1):50-5.

155. Ouchi Y, Kakiuchi T, Okada H, Nishiyama S, Tsukada $H$. The effect of aniracetam on cerebral glucose metabolism in rats after lesioning of the basal forebrain measured by PET. J Neurol Sci. 1999;164(1):7-12.

156. Lieberman JA, Stroup TS, McEvoy JP, et al. Effectiveness of antipsychotic drugs in patients with chronic schizophrenia. N Engl J Med. 2005;353(12): 1209-23.

157. Ader M, Kim SP, Catalano KJ, et al. Metabolic dysregulation with atypical antipsychotics occurs in the absence of underlying disease: a placebocontrolled study of olanzapine and risperidone in dogs. Diabetes. 2005; 54(3):862-71.

158. Sandoval DA, Obici S, Seeley RJ. Targeting the CNS to treat type 2 diabetes. Nat Rev Drug Discov. 2009:8(5):386-98.

159. Cincotta AH, Tozzo E, Scislowski PW. Bromocriptine/SKF38393 treatment ameliorates obesity and associated metabolic dysfunctions in obese (Ob/ Ob) mice. Life Sci. 1997;61(10):951-6.

160. Madiraju AK, Erion DM, Rahimi Y, et al. Metformin suppresses gluconeogenesis by inhibiting mitochondrial glycerophosphate dehydrogenase. Nature. 2014;510(7506):542-6.

161. Ashabi G, Khodagholi F, Khalaj L, Goudarzvand M, Nasiri M. Activation of AMP-activated protein kinase by metformin protects against global cerebral ischemia in male rats: interference of AMPK/PGC-1alpha pathway. Metab Brain Dis. 2014;29(1):47-58.

162. Jiang T, Yu JT, Zhu XC, et al. Acute metformin preconditioning confers neuroprotection against focal cerebral ischaemia by pre-activation of AMPKdependent autophagy. Br J Pharmacol. 2014;171(13):3146-57.

163. Coughlan KA, Valentine RJ, Ruderman NB, Saha AK. AMPK activation: a therapeutic target for type 2 diabetes? Diabetes Metab Syndr Obes. 2014;7:241-53.

164. Labuzek K, Gabryel B, Okopien B. Metformin as a key to alternative activation of microglia? Postepy Hig Med Dosw (Online). 2014;68(0):247-57.

165. Labuzek K, Liber S, Gabryel B, Adamczyk J, Okopien B. Metformin increases phagocytosis and acidifies lysosomal/endosomal compartments in AMPKdependent manner in rat primary microglia. Naunyn Schmiedeberg's Arch Pharmacol. 2010;381(2):171-86

166. Khang R, Park C, Shin JH. The biguanide metformin alters phosphoproteomic profiling in mouse brain. Neurosci Lett. 2014;579:145-50.

167. Abd-Elsameea AA, Moustaf AA, Mohamed AM. Modulation of the oxidative stress by metformin in the cerebrum of rats exposed to global cerebral ischemia and ischemia/reperfusion. Eur Rev Med Pharmacol Sci. 2014;18(16): 2387-92.

168. Nath N, Khan M, Paintlia MK, et al. Metformin attenuated the autoimmune disease of the central nervous system in animal models of multiple sclerosis. J Immunol. 2009;182(12):8005-14.

169. Potts MB, Lim DA. An old drug for new ideas: metformin promotes adult neurogenesis and spatial memory formation. Cell Stem Cell. 2012;11(1):5-6.

170. Wang J, Gallagher D, DeVito LM, et al. Metformin activates an atypical PKCCBP pathway to promote neurogenesis and enhance spatial memory formation. Cell Stem Cell. 2012;11(1):23-35.
171. Williams T, Courchet J, Viollet B, Brenman JE, Polleux F. AMP-activated protein kinase (AMPK) activity is not required for neuronal development but regulates axogenesis during metabolic stress. Proc Natl Acad Sci U S A. 2011;108(14):5849-54.

172. Li J, Deng J, Sheng W, Zuo Z. Metformin attenuates Alzheimer's disease-like neuropathology in obese, leptin-resistant mice. Pharmacol Biochem Behav. 2012;101(4):564-74.

\section{Publisher's Note}

Springer Nature remains neutral with regard to jurisdictional claims in published maps and institutional affiliations.
Ready to submit your research? Choose BMC and benefit from:

- fast, convenient online submission

- thorough peer review by experienced researchers in your field

- rapid publication on acceptance

- support for research data, including large and complex data types

- gold Open Access which fosters wider collaboration and increased citations

- maximum visibility for your research: over $100 \mathrm{M}$ website views per year

At BMC, research is always in progress.

Learn more biomedcentral.com/submissions 